Aim of the study: We aimed to assess the alterations of serum C-reactive protein (CRP) and albumin levels in colorectal cancer patients who underwent preoperative radio(chemo)therapy and those who did not.

Material and methods: The determinations of albumin and CRP were performed before and at 2, 3, 5 and 7 days after surgery in 60 colorectal cancer patients. 25 healthy subjects served as a reference group. For each patient the modified Glasgow Prognostic Score (mGPS) was calculated.

Results: On the operation day CRP and albumin concentrations were not different in preoperatively treated or radiotherapy naïve patients. On postoperative day 2, 3, 5 and 7 no significant differences were observed between the two groups, with the only exception for albumin concentration, which was significantly higher on postoperative days 2 and 7 in the radiation naïve group. In all patients perioperative alterations of serum CRP level were significant at all time points (preoperatively vs. day 2 , day 2 vs. day 3 , day 3 vs. day 5 , day 5 vs. day 7). The albumin decrease from the preoperative day to postoperative day 2 was significant, as was its increase from postoperative day 3 to 5 .

Conclusions: We have seen no differences in the CRP and albumin concentrations in preoperatively irradiated versus non-irradiated colorectal cancer patients on the day of surgery and on postoperative days $2,3,5$ and 7 . There were, however, significant concentration changes in the value of these two serum markers from preoperatively to postoperative day 2 and over the following postoperative week, but presumably related to the surgical trauma, not the neoadjuvant treatment.

Key words: colorectal cancer, CRP, albumin, neoadjuvant therapy.

\section{Preoperative radiotherapy does not alter pre- and early postoperative serum C-reactive protein and albumin concentrations in colorectal cancer patients}

\author{
Wojciech M. Wysocki ${ }^{1}$, Zofia Stasik², Zbigniew Darasz ${ }^{1}$, Jerzy Jakubowicz ${ }^{3}$, \\ Jadwiga Tarapacz', Jan Kanty Kulpa \\ Department of Surgical Oncology, Centre of Oncology - Maria Skłodowska-Curie \\ Memorial Institute, Cracow Branch, Poland \\ 2Department of Clinical Biochemistry, Centre of Oncology - Maria Skłodowska-Curie \\ Memorial Institute, Cracow Branch, Poland \\ ${ }^{3}$ Department of Gastrointestinal and Urological Cancers, Centre of Oncology - \\ Maria Skłodowska-Curie Memorial Institute, Cracow Branch, Poland
}

\section{Introduction}

Commonly accepted management of colorectal cancer patients includes preoperative radiotherapy or radiochemotherapy for the majority of rectal cancers [1]. Irradiation to the lower rectum may cause a local inflammatory reaction, which was confirmed in the pathology report in at least $1 / 3$ of patients [2]. On the other hand, this treatment strategy is claimed to suppress immunological system functioning [3, 4]. Therefore we decided to assess the alterations of serum C-reactive protein (CRP), a basic marker of inflammatory response, and albumin levels in colorectal cancer patients who underwent preoperative radio(chemo)therapy and those who did not. We also analyzed the influence of neoadjuvant therapy on the changes in the levels of the two above-mentioned parameters in both groups during 7 postoperative days, to see if there were any delayed differences between irradiated and radiation naïve groups.

\section{Material and methods}

The present study was conducted in 60 patients with non-metastatic colorectal cancer in different stages of disease, with no clear clinical signs of infection. Twenty of them received neoadjuvant treatment - radiotherapy (25 Gy) or radiochemotherapy (45-60 Gy) - while 40 patients underwent surgery alone. All patients underwent surgical resections of various types, all with radical intent. The interval between neoadjuvant therapy and surgery was 1-6 weeks. Patients who developed early postoperative complications (including infections) were not included in the analysis.

An age-matched group of 25 healthy subjects served as the reference group. The determinations of C-reactive protein (CRP) and albumin (ALB) were performed before and 2, 3, 5 and 7 days after surgery.

Peripheral venous blood samples were obtained from all patients and controls by a standard procedure, between 8 and 9 a.m., in fasting state. Serum CRP concentrations were measured by immunonephelometric technique, using a Siemens reagent kit and a ProSpec nephelometer. The albumin levels were determined on the basis of total protein concentration measured by a biuret method and the percentage of electrophoretic fractions calculated after separating proteins by capillary electrophoresis. 
For each participant the mGPS index was calculated. mGPS was defined as follows: patients with both elevated CRP (> $10 \mathrm{mg} / \mathrm{l})$ and hypoalbuminemia $(<35 \mathrm{~g} / \mathrm{l})$ were

Table 1. Comparison of C-reactive protein (CRP) and albumin (ALB) concentrations in irradiated and radiation naïve colorectal cancer patients preoperatively and over 7 postoperative days

\begin{tabular}{|c|c|c|c|c|}
\hline Parameter & & $\begin{array}{l}\text { Preoperative } \\
\text { radiotherapy } \\
\text { - chemotherapy) } \\
\quad n=20\end{array}$ & $\begin{array}{c}\text { Surgery } \\
\text { only } \\
n=40\end{array}$ & $p$ \\
\hline \multicolumn{5}{|c|}{ Preoperatively } \\
\hline CRP $[\mathrm{mg} / \mathrm{l}]$ & $\begin{array}{l}\text { median } \\
\text { range }\end{array}$ & $\begin{array}{c}4.41 \\
0.16-81.8\end{array}$ & $\begin{array}{c}5.38 \\
0.2-58.5\end{array}$ & NS \\
\hline ALB [g/l] & $\begin{array}{l}\text { median } \\
\text { range }\end{array}$ & $\begin{array}{c}36.8 \\
29.7-42.2\end{array}$ & $\begin{array}{c}38.3 \\
21.6-45.2\end{array}$ & NS \\
\hline mGPS O [\%] & & $70 \%$ & $55 \%$ & \\
\hline \multicolumn{5}{|c|}{ Postoperative day 2} \\
\hline CRP $[\mathrm{mg} / \mathrm{l}]$ & $\begin{array}{l}\text { median } \\
\text { range }\end{array}$ & $\begin{array}{c}117.0 \\
24.5-473.0\end{array}$ & $\begin{array}{c}109.5 \\
31.1-206.0\end{array}$ & NS \\
\hline $\mathrm{ALB}[\mathrm{g} / \mathrm{l}]$ & $\begin{array}{l}\text { median } \\
\text { range }\end{array}$ & $\begin{array}{c}26.9 \\
24.6-35.6\end{array}$ & $\begin{array}{c}29.1 \\
22.7-34.9\end{array}$ & 0.03 \\
\hline \multicolumn{5}{|c|}{ Postoperative day 3} \\
\hline $\mathrm{CRP}[\mathrm{mg} / \mathrm{l}]$ & $\begin{array}{l}\text { median } \\
\text { range }\end{array}$ & $\begin{array}{c}71.75 \\
17.5-203.0\end{array}$ & $\begin{array}{c}80.75 \\
31.6-175.0\end{array}$ & NS \\
\hline ALB $[g / l]$ & $\begin{array}{l}\text { median } \\
\text { range }\end{array}$ & $\begin{array}{c}26.8 \\
23.4-39.4\end{array}$ & $\begin{array}{c}29.0 \\
22.4-36.8\end{array}$ & NS \\
\hline \multicolumn{5}{|c|}{ Postoperative day 5} \\
\hline CRP $[\mathrm{mg} / \mathrm{l}]$ & $\begin{array}{l}\text { median } \\
\text { range }\end{array}$ & $\begin{array}{c}24.1 \\
7.31-95.5\end{array}$ & $\begin{array}{c}13.7 \\
2.15-119.0\end{array}$ & NS \\
\hline $\mathrm{ALB}[\mathrm{g} / \mathrm{l}]$ & $\begin{array}{l}\text { median } \\
\text { range }\end{array}$ & $\begin{array}{c}30.2 \\
24.2-36.3\end{array}$ & $\begin{array}{c}31.6 \\
24.0-38.3\end{array}$ & NS \\
\hline \multicolumn{5}{|c|}{ Postoperative day 7} \\
\hline CRP $[\mathrm{mg} / \mathrm{l}]$ & $\begin{array}{l}\text { median } \\
\text { range }\end{array}$ & $\begin{array}{c}14.0 \\
7.03-79.7\end{array}$ & $\begin{array}{c}13.7 \\
2.15-119.0\end{array}$ & NS \\
\hline $\mathrm{ALB}[\mathrm{g} / \mathrm{l}]$ & $\begin{array}{l}\text { median } \\
\text { range }\end{array}$ & $\begin{array}{c}30.0 \\
25.8-36.6\end{array}$ & $\begin{array}{c}31.6 \\
24.0-38.3\end{array}$ & 0.01 \\
\hline
\end{tabular}

NS - non signification allocated a score of 2. Patients in whom neither of these abnormalities was present were allocated a score of 0 . Patients with an elevated CRP alone were scored as 1 while those with hypoalbuminemia alone were scored as 0.

Statistical analyses were done using STATISTICA version 9 (StatSoft). The statistical evaluation of differences between the results in the investigated groups was based on nonparametric Kruskal-Wallis test. In the analysis of relationships between concentrations of determined parameters, Pearson correlation coefficients were calculated. Differences were considered statistically significant if the $P$-value was below 0.05 .

\section{Results}

The serum CRP concentration was significantly elevated (median $4.7 \mathrm{vs} .1 .6 \mathrm{mg} / \mathrm{l}, p=0.0001$ ), and albumin level was significantly lowered (median 37.6 vs. $42.7 \mathrm{~g} / \mathrm{l}, p=0.0000$ ) in colorectal cancer patients versus healthy controls. In the study group elevated CRP ( $>5 \mathrm{mg} / \mathrm{l}$ ) level and hypoalbuminemia $(<35 \mathrm{~g} / \mathrm{l})$ were observed in $48.3 \%$ (29/60) and $21.7 \%$ $(13 / 60)$, respectively. Moreover, a significant reciprocal correlation between CRP and albumin levels $(r=-0.376, p=0.003)$ was found.

On the operation day CRP and albumin concentrations were not different between preoperatively irradiated and radiotherapy naïve patients (Table 1 ). However, modified GPS (mGPS) values of 0 revealed a weak tendency to more frequent occurrence in the radiotherapy naïve group of patients (70\% vs. $55 \%$; not significant). On postoperative day 2, 3, 5 and 7 no significant differences were observed between the two groups, with the only exception for albumin concentration, which was significantly higher on postoperative days 2 and 7 in the radiation naïve group (Table 1). The frequency of elevated CRP and decreased albumin levels in both analyzed groups of patients was similar and in the postoperative period equal to or close to 100\% (Fig. 1). In all patients (irradiated and radiation naïve combined) perioperative alterations of serum CRP level were significant at all time points (preoperatively vs. day 2 , day 2 vs. day 3 , day 3 vs. day 5 , day 5 vs. day 7 ). Albumin decrease from the preoperative day to postoperative day 2 was sig-

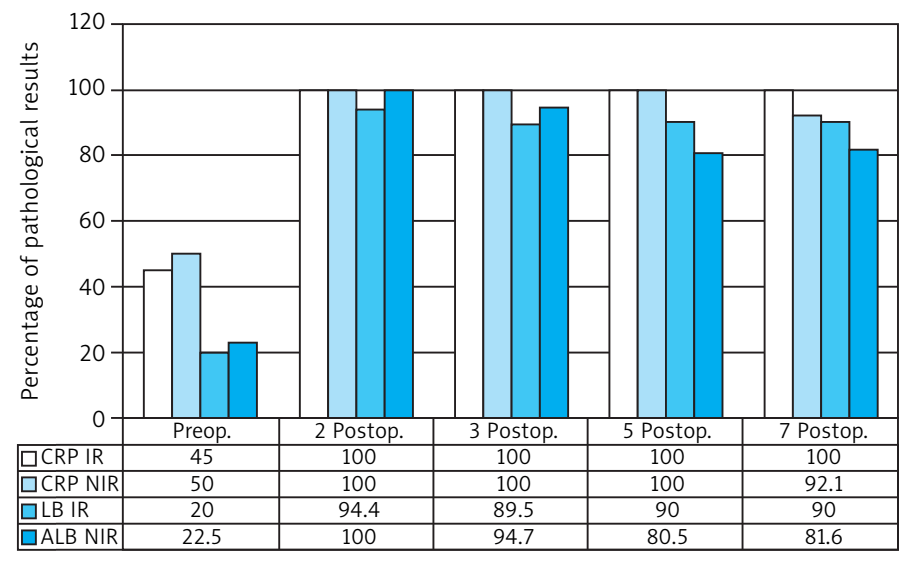

Fig. 1. Percentages of pathological serum C-reactive protein (CRP) and albumin (ALB) levels pre- and postoperatively in irradiated (IR) and radiation naïve (NIR) groups 
Table 2. Alterations of median C-reactive protein (CRP) and albumin (ALB) levels at the consecutive time points

\begin{tabular}{|c|c|c|c|c|c|c|c|c|c|c|}
\hline & & Preop. & $p$ & 2 days postop. & $p$ & 3 days postop. & $p$ & 5 days postop. & $p$ & 7 days postop. \\
\hline $\mathrm{CRP}[\mathrm{mg} / \mathrm{l}]$ & $\begin{array}{l}\text { median } \\
\text { range }\end{array}$ & $\begin{array}{c}4.67 \\
0.16-81.8\end{array}$ & 0.0000 & $\begin{array}{c}110.5 \\
24.5-473.0\end{array}$ & 0.002 & $\begin{array}{c}76.6 \\
17.5-203.0\end{array}$ & 0.0000 & $\begin{array}{c}28.3 \\
6.1-97.7\end{array}$ & 0.0000 & $\begin{array}{c}13.8 \\
2.1-119.0\end{array}$ \\
\hline $\mathrm{ALB}[\mathrm{g} / \mathrm{l}]$ & $\begin{array}{l}\text { median } \\
\text { range }\end{array}$ & $\begin{array}{c}37.6 \\
21.6-45.2\end{array}$ & 0.0000 & $\begin{array}{c}28.3 \\
22.7-35.6\end{array}$ & NS & $\begin{array}{c}27.9 \\
22.4-39.4\end{array}$ & 0.0000 & $\begin{array}{c}30.6 \\
24.2-39.5\end{array}$ & NS & $\begin{array}{c}30.7 \\
24.0-38.3\end{array}$ \\
\hline
\end{tabular}

nificant, as was its gradual increase from postoperative day 3 to 5 (Table 2).

\section{Discussion}

Radiotherapy, commonly used as neoadjuvant treatment in rectal cancer patients (in advanced cases combined with chemotherapy) [1], causes a local, peritumoral inflammatory reaction (as seen on histopathology) in the pelvis in at least 1/3 of patients [2]. Koc et al. reported that CRP, a major acute phase protein, was significantly elevated in patients with different malignancies, including colorectal cancer, by the end of preoperative or definitive radiotherapy. Unfortunately, the authors did not specify how long the CRP was elevated after irradiation $[5,6]$. In the study group irradiation was performed 1-6 weeks before surgery. Elevated CRP was seen in $45 \%$ of previously irradiated patients and $50 \%$ of radiation naïve patients. In a study by Ki et al. the authors observed a steady increase of CRP level during 35 fractions of radiotherapy for head-and-neck cancer and importantly they also observed marked elevation of CRP (as compared to the baseline) for at least 2 weeks after irradiation [7]. Long lasting elevation of CRP confirms that local radiationinduced inflammation lasts at least a few weeks after radiotherapy, keeping CRP synthesis active (CRP half-life is only about 19 hours) [8].

Mahdavi and colleagues observed significantly lowered albumin levels in patients who underwent irradiation (pelvic included) [10]. Apart from radiation, another factor potentially leading to hypoalbuminemia is that colorectal cancer patients are often malnourished, as the natural course of disease results in lack of appetite, weight loss, etc. It should be noted that changes in the albumin concentration, due to the half-life of this protein (ca. 20 days), follow relatively slowly and are less characteristic [11]. We observed albumin concentration $<35 \mathrm{~g} / \mathrm{l}$ in $20 \%$ of preoperatively irradiated patients and in $22.5 \%$ of radiotherapy naïve patients.

An important role in the synthesis of CRP in the liver is attributed to interleukin 6 (IL-6), which, together with TNF- $\alpha$, is assigned a primary role in the development of the inflammatory response. On the other hand, many studies have documented elevated levels of IL-6 in cancer, including colorectal cancer [9]. However, contrary to that, there are reports showing a detrimental effect of preoperative radio(chemo)therapy on immunological functions in rectal cancer patients, e.g. a significant decrease in IL-6 concentration was seen [4]. The suppression of the immune system in patients receiving neoadjuvant therapy for rectal cancer was recently confirmed [3]. The lack of significant difference between the two groups of patients in CRP and albumin concentrations, both before and during a 7-day post-operative period, may indirectly indicate the complexity of the mechanisms of IL-6 action stimulating the inflammatory response.

We hypothesized that pelvic radiation-induced inflammation should be reflected by alterations in serum CRP and albumin concentrations. Based on the above studies, we expected increased CRP and decreased albumin in the serum in preoperatively irradiated patients. We could not compare CRP and albumin levels before and after irradiation, as the blood samples taken before radiotherapy were not available, but we did compare irradiated and non-irradiated colorectal cancer patients and observed no differences in serum CRP and albumin between these two groups. To ensure the methodology, we checked if preoperative CRP and albumin levels in our group of colorectal cancer patients were significantly altered as compared to healthy controls, and we confirmed a significant difference in this regard only (as present in the literature) [12]. It is interesting that both previously irradiated and non-irradiated patients had a CRP level not significantly different compared to healthy controls. Additionally, we also followed CRP and albumin levels on postoperative days 2, 3, 5 and 7 in both groups (irradiated and not irradiated), and observed no significant differences between the groups postoperatively (Table 1), with the only exception for albumin concentration, which was significantly higher 2 and 7 days postoperatively in the radiation naïve group - but the magnitude of this difference was of no clinical importance $(2.2 \mathrm{~g} / \mathrm{l}$ and $1.6 \mathrm{~g} / \mathrm{l}$, respectively). Obviously, as seen in Table 1, in both groups there was a rise in CRP postoperatively, and a slight albumin drop, but these changes (parallel in both groups) can be attributed to the surgical trauma itself.

We also noted that the median concentration of CRP in both of our groups of patients was markedly higher as compared to other studies evaluating CRP after radiotherapy for other malignancies: CRP after radiotherapy in endometrial and cervical cancer was $2.4 \mathrm{mg} / \mathrm{l}$ [6] and for head-and-neck cancer was $2.12 \mathrm{mg} / \mathrm{l}$ [7]. In our group the median was 4.41 $\mathrm{mg} / \mathrm{l}$ (moreover in our study it was non-significantly lower compared to the radiation naïve group). We attribute this observation to the specific biology of colorectal cancers in general, with relatively slow progression accompanied by peritumoral inflammation (mainly in colon cancer cases). The pronounced increase in the postoperative CRP level is, as mentioned before, associated with trauma related to the major, extensive surgical resection.

In conclusion, preoperative CRP and albumin levels in colorectal cancer patients were altered compared to healthy controls. We observed no differences in the CRP and albumin concentrations in preoperatively irradiated versus non-irradiated colorectal cancer patients on the day of surgery and on post- 
operative days 2, 3, 5 and 7. There were, however, significant concentration changes in the value of these two serum markers from preoperative to postoperative (day 2 and over the following postoperative week) values, but they were presumably related to the surgical trauma.

Authors declare no conflict of interest.

\section{References}

1. Glimelius B, Påhlman L, Cervantes A on behalf of the ESMO Guidelines Working Group. Rectal cancer: ESMO Clinical Practice Guidelines for diagnosis, treatment and follow-up. Ann Oncol 2010; 21 (Suppl 5): v82-6.

2. Perez RO, Habr-Gama A, dos Santos RM, Proscurshim I, Campos FG, Rawet V, Kiss D, Cecconello I. Peritumoral inflammatory infiltrate is not a prognostic factor in distal rectal cancer following neoadjuvant chemoradiation therapy. J Gastrointest Surg 2007; 11: 1534-40.

3. Kerr SF, Klonizakis M, Glynne-Jones R. Suppression of the postoperative neutrophil leucocytosis following neoadjuvant chemoradiotherapy for rectal cancer and implications for surgical morbidity. Colorectal Dis 2010; 12: 549-54.

4. Wichmann MW, Meyer G, Adam M, et al. Detrimental immunologic effects of preoperative chemoradiotherapy in advanced rectal can cer. Dis Colon Rectum 2003; 46: 875-87.

5. Koc M, Taysi S, Sezen O, Bakan N. Levels of some acute-phase proteins in the serum of patients with cancer during radiotherapy. Biol Pharm Bull 2003; 26: 1494-7.

6. Cengiz M, Akbulut S, Atahan IL, Grigsby PW. Acute phase response during radiotherapy. Int J Radiat Oncol Biol Phys 2001; 49: 1093-6.

7. Ki Y, Kim W, Nam J, Kim D, Park D, Kim D. C-reactive protein levels and radiation-induced mucositis in patients with head-and-neck cancer. Int J Radiat Oncol Biol Phys 2009; 75: 393-8.

8. Vermeire S, Van Assche G, Rutgeerts P. C-reactive protein as a marker for inflammatory bowel disease. Inflamm Bowel Dis 2004; 10: 661-5.

9. Aggarval BB, Shishodia A, Sandur SK, Pandey MK, Sethi G. Inflammation and cancer: How hot is the link? Biochem Pharmacol 2006; 72: 1605-21.

10. Mahdavi R, Faramarzi E, Mohammad-Zadeh M, Ghaeammaghami J, Jabbari MV. Consequences of radiotherapy on nutritional status, dietary intake, serum zinc and copper levels in patients with gastrointestinal tract and head and neck cancer. Saudi Med J 2007; 28: 435-40.

11. Ingenbleck Y. Transthyretin (prealbumin) in health and disease: Nutritional implications. Ann Rev Nutr 1994; 14: 495-533.

12. Kwon KA, Kim SH, Oh SY, et al. Clinical significance of preoperative serum vascular endothelial growth factor, interleukin-6, and C-reactive protein level in colorectal cancer. BMC Cancer 2010; 10: 203.

\section{Address for corresspondence}

Prof. Jan Kanty Kulpa

Centrum Onkologii Instytut im. M. Skłodowskiej-Curie

Krakow Branch

Garncarska 11

31-115 Kraków, Poland

tel. +48124228760

e-mail: z5jkulpa@cyf-kr.edu.pl

Submitted: 1.09 .2012

Accepted: 6.11 .2012 